\title{
Analysis of differences between images with lighting from different directions for detection of tool wear
}

\author{
Wykrywanie zużycia ostrza na podstawie analizy różnic \\ pomiędzy zdjęciami z oświetleniem z różnych kierunków
}

In developing a vision-based system, the most important thing is choosing the lighting. Properly set up simplifies image analysis. The prototype of the system for detecting wear of flank face, which detects the differences between successive images of the same tool illuminated from different directions, has been developed.

KEYWORDS: tool condition monitoring, cutting, machine vision

Diagnosis of the condition of the cutting tool is a prerequisite for the automation of manufacturing, which is aimed at ensuring the proper quality of the manufacture of the articles. It is particularly important in the aviation industry, where expensive objects are often made. A high wear blade may cause damage to the workpiece, which results in premature tool replacement. This results in an increase in the costs of machine downtime during rebuilding and purchase of more tools.

In many centers around the world, this has inspired the development of a blade diagnostic system. The most widely used solutions for blade wear are the most commonly used [1,2], for example, based on signals from force sensors, vibrations, acoustic emissions and power. An example of this is an automatic blade diagnostic system developed at the Warsaw University of Technology [3, 4], Automation and Machining Department. Another approach to the intermediate assessment of the blade state is the visual evaluation of chips [5].

These methods of assessing the state of the blade use indirect diagnostics, and thus require the connection of a certain measured quantity with the degree of wear of the blade. An alternative approach would be to use direct indicators. These include geo-metric dimensions describing tool wear. One method uses tool probes that measure mechanical wear [6] by direct contact with the tool, measuring tool tip offset. The most accurate wear measurements can be carried out with workshop microscopes, but it requires a machine tool image, which consumes a lot of time and is unacceptable in industrial practice. A separate, growing group of diagnostic techniques is the use of automated vision methods [7].

\footnotetext{
* Mgr inż. Krzysztof Błażejak (krzysztof.blazejak@gmail.com) Zakład Automatyzacji i Obróbki Skrawaniem Politechniki Warszawskiej
}

Direct observation of the tool at intervals is a promising way to obtain geometric parameters that can be used as accurate blade wear indicators. The basic criterion for solving problems in video methods is proper selection of equipment for the projected solution. It is important to choose the camera and the lens, but the key is the lighting. A well-made photo simplifies further digital processing.

The simplest approach to detecting a worn tool area is to light the blade and look for reflexes, which are usually much more noticeable on the shaved part than on an unused tool. This approach was used in [8].

More complex systems offer controlled lighting. In [9], an innovative approach with two fiber optics is used to illuminate the tool. The light sources could be adjusted smoothly, which allowed for a proper flushing of the wear zone. The concept of controlled lighting was developed by using a ring light [10] to illuminate the tool from different directions. Pictures are compared with each other in terms of moving contours. Those that do not move are considered contours of wear. This allows you to reduce the effect of reflections that shift depending on the angle of illumination.

In this paper, we decided to use an illuminator to illuminate the blade from 8 independent directions. Analysis of differences between subsequent images allows for a relatively simple and independent separation of the wear area, which makes it possible to conduct diagnostics of the tool state during machining breaks.

\section{Description of automatic wear estimation}

A special optical kit consisting of the Basler Aviator avA2300-25gm camera with Schneider APO-CPN 4.0/60 lens mounted on a $125 \mathrm{~mm}$ distance was used to determine blade wear. The smallest possible aperture is set, which ensures maximum depth of field. Between the lens and the photographed tool was a specially designed light for this purpose. It was built from LL-R2835VC-V1HM30 light-emitting diodes, located on the periphery of the optical system in 8 groups of 13 diodes. The system user selects which segments to fire during the shot. The diodes are red in color, as shooting with monochrome light reduces the chromatic aberration error of the lens. The measuring system is shown schematically in fig. 1. 


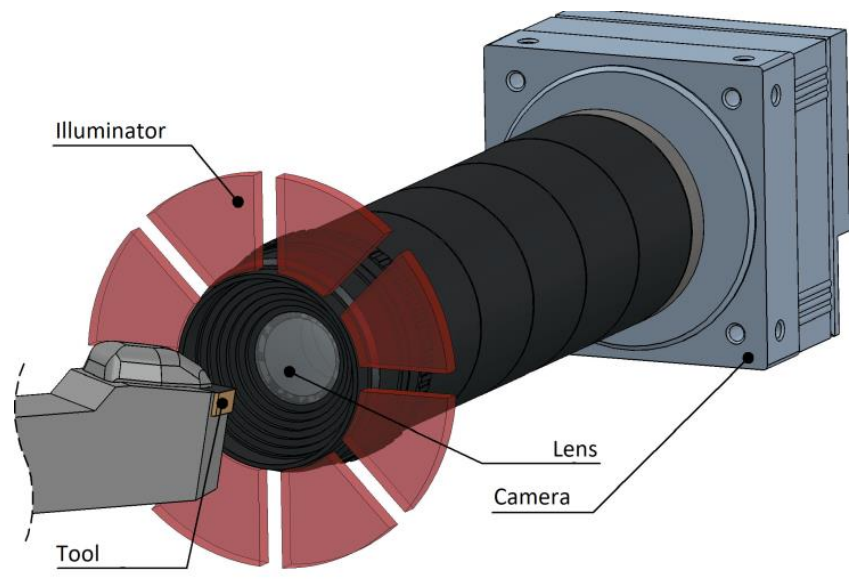

Fig. 1. Diagram of a measuring system used for differential analysis of photographs

Fig. 2 shows segments of LEDs selected for lighting the analyzed blade. Photographs were selected where the illumination of the application surface was similar, with large differences in the area of wear. These pictures are shown in fig. 3 (photo $A$ ) and fig. 4 (photo $B$ ).

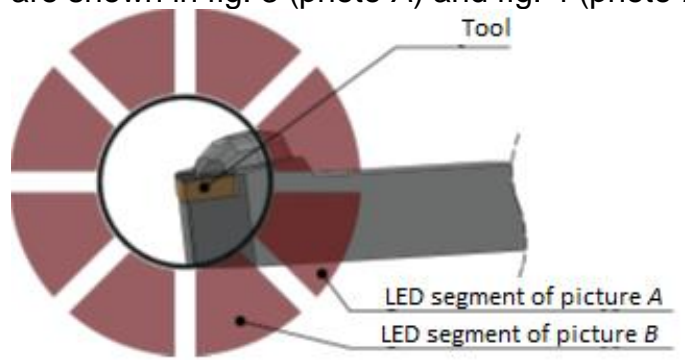

Fig. 2. Selected LED segments for sample analysis of blades; view from the perspective of the lens

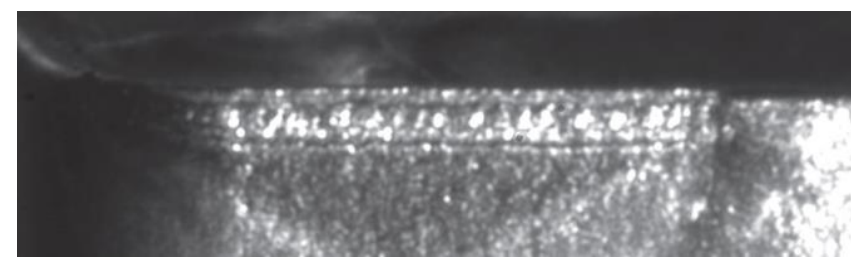

Fig. 3. Picture $A$ as a minuend in differential analysis

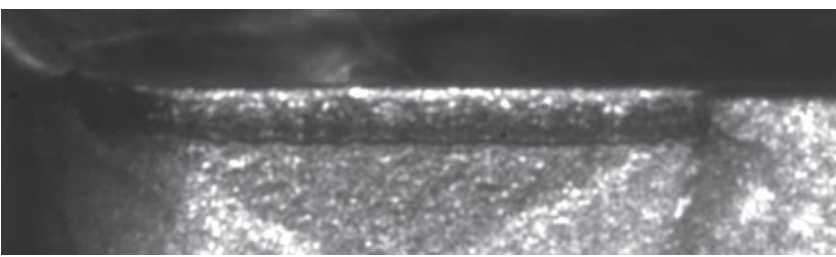

Fig. 4. Photo $B$ as a subtrahend in differential analysis

Photographs $A$ and $B$, with the illumination of the object at different angles, show the greatest difference in the wear area. Fig. 5 shows the algebraic difference between images $A$ and $B$.

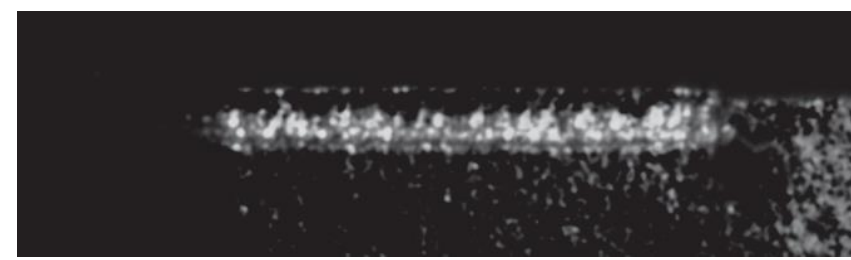

Fig. 5. Difference between photos $A$ and $B$
The result of subtraction of both images was followed by a threshold operation (fig. 6) that converted an 8-bit grayscale image into a binary image capable of performing morphological operations that purge image from noise.

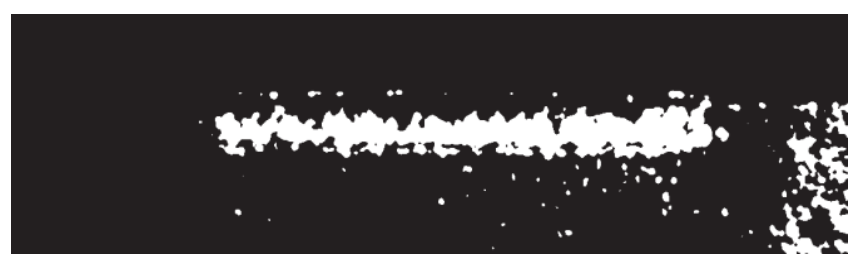

Fig. 6 . The result of the difference threshold between images $A$ and $B$

In the image after threshold operation, there are usually slight disturbances that do not fall into the wear area. In order to get rid of them, it was necessary to use the removal of small objects, the effect of which is shown in fig. 7.

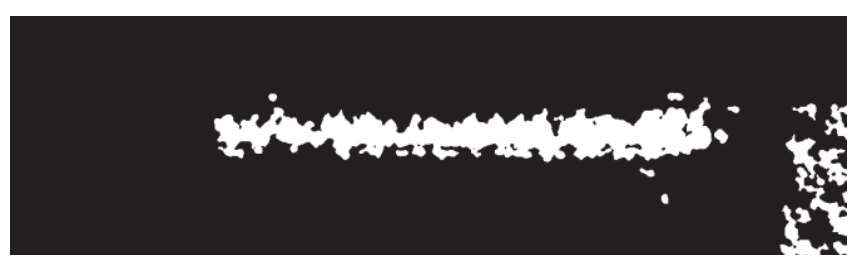

Fig. 7. Result of morphological operation - removal of small objects

The next step was to apply dilatation operations to unify the edges of the wear area. The result is shown in fig. 8 .

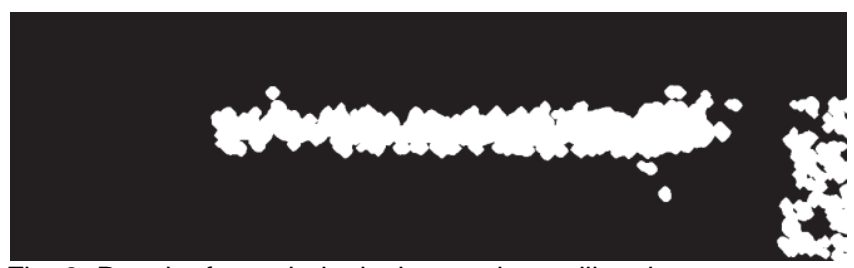

Fig. 8. Result of morphological operation - dilatation

In the area of wear, small inclusions are often present, which are removed by filling the holes in the objects, as shown in fig. 9.

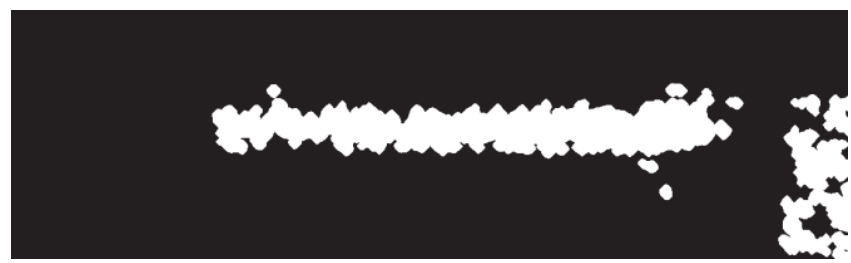

Fig. 9. Result of morphological operation - filling of holes

The next step was to restore the objects to their original dimensions that were lost as a result of the dilatation. For this purpose, an inverse operation, i.e. erosion, is applied, the effect of which is shown in fig. 10.

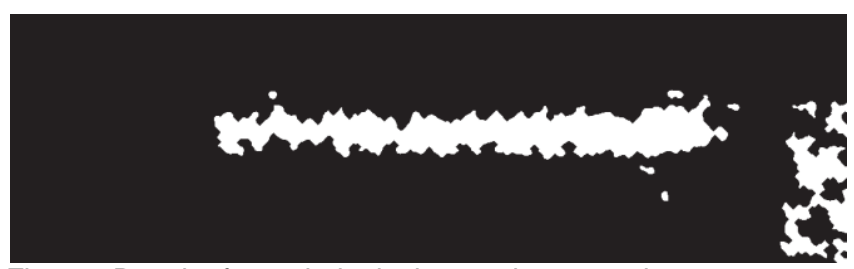

Fig. 10. Result of morphological operation - erosion 
Fig. 11 shows the effects of removing small objects. However, this time it included larger elements.

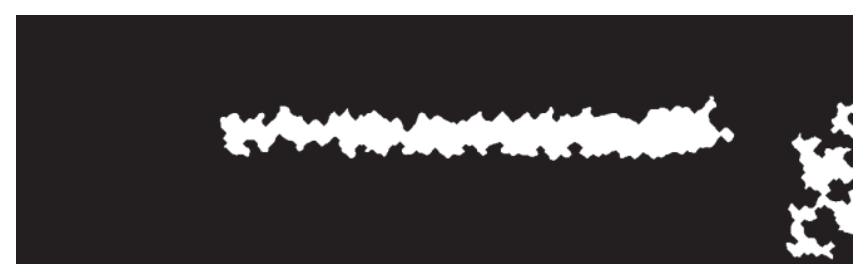

Fig. 11. Result of morphological operation - removal of small objects

Only the desired area of wear and shine at the edge was visible in the image. With the removal of boundary objects (fig. 12), the image was brought into a state, where only the surface of the relief was visible.

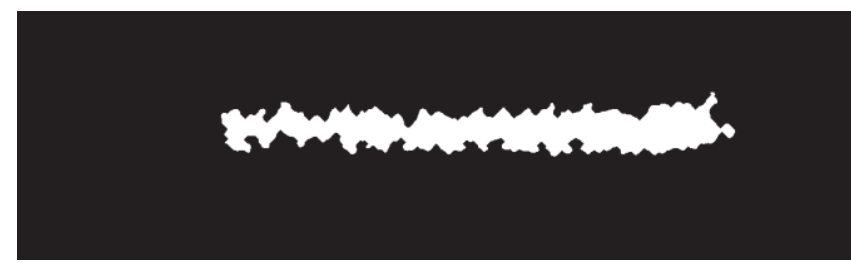

Fig. 12. Result of morphological operation - removal of edge objects

Fig. 13 shows the effect of applying the area of fig. 12 to image $B$ of fig. 4. Two green lines are also visible. The top corresponds to the main cutting edge (its detection is carried out on an unconverted image where the entire thickness of the plate is visible, by covering its lower edge - which is more resistant to interference - and then offset by known plate thickness). On the other hand, the lower line corresponds to the lowest point in the wear area. The distance between these lines is one of the most common direct wear indicators $-V B_{B \max }$ (defined in ISO 3685:1993).

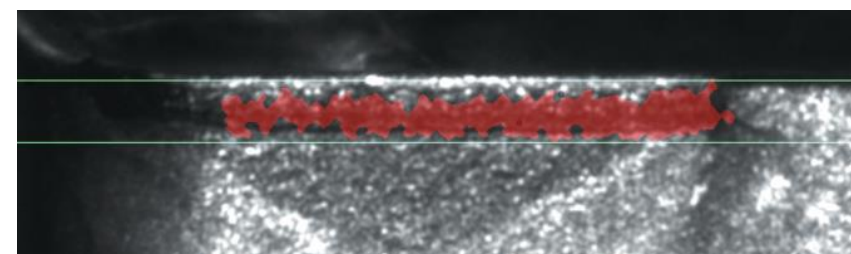

Fig. 13. Photo $B$ with marked wear (red color) and cutting edge lines and maximum downward point of wear area (green lines)

In addition, to avoid interference, a series of pairs of images with different exposure times are performed: 167 ms, $206 \mathrm{~ms}, 244 \mathrm{~ms}, 283 \mathrm{~ms}, 322 \mathrm{~ms}, 361 \mathrm{~ms}$ and 400 ms. The consumption measurement is performed for all pairs, and the smallest measured value is taken as the wear value.

\section{Verifying the algorithm operation}

During the experiment, 18HGT steel was machined on a TUD-50 with a DSDNN 2020K 12 with a mounted SNMG $120408 \mathrm{PM}$ 4325. Cutting speed was $v_{c}=250$ $\mathrm{m} / \mathrm{min}$, cutting depth $a_{p}=1.8 \mathrm{~mm}$ and feedrate $f=0.16$ $\mathrm{mm} / \mathrm{rev}$. The wear criterion was $V B_{B \max }=0.3 \mathrm{~mm}$. The algorithm was scaled to detect wear of near blunt blades as it was impossible to find universal morphological transformation parameters. As a result, its correct operation starts for $V B_{B \max }$ above $0.15 \mathrm{~mm}$.

The results of wear measurements as a function of time are shown in fig. 14. It shows the results of the described algebraic test performed automatically and the mean of the measurements made by hand by three independent persons. The mean difference between manual and automatic measurements was $14.5 \mu \mathrm{m}$ with a standard deviation of $10.6 \mu \mathrm{m}$.

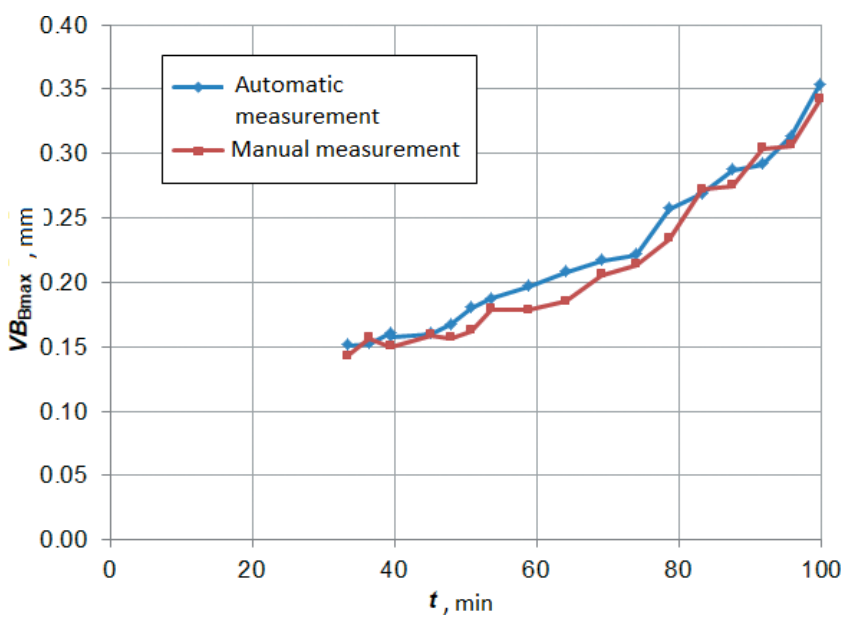

Fig. 14. Dependence of measured wear from cutting time

\section{Conclusions}

The described method of automatically determining the wear of a blade from a photo has its limitations, requiring the user to use a calibration system for image processing parameters for a specific amount of wear indicator. However, within a certain range, it works properly and stably.

The method seems promising, especially for the aviation industry, where it is common practice to replace sharp tools with new ones to avoid damage to expensive items during machining. Introducing diagnostics directly on the machine would make it possible to significantly reduce the cost of setting up the machine.

\section{REFERENCES}

1. Teti R., Jemielniak K., O’Donnell G., Dornfeld D. „Advanced monitoring of machining operations". CIRP Annals - Manufacturing Technology. 59, 2 (2010): pp. 717-739.

2. Siddhpura A., Paurobally R. „A review of flank wear prediction methods for tool condition monitoring in a turning proces". International Journal of Advanced Manufacturing Technology. 65, 1-4 (2013): pp. 371-393.

3. Jemielniak K., Urbański T., Kossakowska J., Bombiński S. „Tool condition monitoring based on numerous signal features". International Journal of Advanced Manufacturing Technology. 59, 1-4 (2012): pp. 73-81.

4. Bombiński S., Błażejak K., Nejman M., Jemielniak K. „Sensor Signal Segmentation for Tool Condition Monitoring". 7th HPC 2016 - CIRP Conference on High Performance Cutting. (2016): pp. 155160.

5. Żaczek J., Kossakowska J., Bombiński S. „Analiza możliwości wykorzystania systemu wizyjnego do rozpoznawania typu wiórów”. Inżynieria Maszyn. 19, 1 (2014): pp. 102-114.

6. Chrzanowski J. „Sonda narzędziowa z funkcją pomiaru zużycia ostrza”. Mechanik. 12 (2015): pp. 14-17.

7. Dutta S., Pal S.K., Mukhopadhyay S., Sen R. „Application of digital image processing in tool condition monitoring: A review". CIRP Journal of Manufacturing Science and Technology. 6, 3 (2013): pp. 212-232.

8. Weis W. „Tool wear measurement on basis of optical sensors, vision systems and neuronal networks (application milling)". Proceedings of WESCON '93. (1993): pp. 134-138.

9. Kurada S., Bradley C. „A machine vision system for tool wear assessment". Tribology International. 30, 4 (1997): pp. 295-304. 10. Pfeifer T., Wiegers L. ,Reliable tool wear monitoring by optimized image and illumination control in machine vision". Measurement: Journal of the International Measurement Confederation. 28 , 3 (2000): pp. 209-218. 